\title{
Epidemiological features of Lymphoma in Pakistan
}

\author{
Samreen Shabbir ${ }^{1 *}$, Khush Naseeb Ahmed ${ }^{2}$, Mehjabeen Marri², Mehreen \\ Mengal $^{2}$, Muhammad Hashim Jan ${ }^{1}$, Muhammad Sharif Jamali ${ }^{1}$, Naeema \\ Anwar $^{1}$, Saeeda Khanum ${ }^{1}$ and Sheikh Ahmed ${ }^{1}$ \\ 1. Institute of Biochemistry, University of Balochistan Quetta, 87300-Pakistan \\ 2. Center for Nuclear medicine and Radiotherapy (CENAR) Quetta-Pakistan \\ *Corresponding author's email: samreenshabir40@gmail.com \\ Citation \\ Epidemiological features of Lymphoma in Pakistan. SamreenShabbir, KhushNaseeb Ahmed, Mehjabeen Marri, \\ MehreenMengal, Muhammad Hashim Jan, Muhammad Sharif Jamali, Naeema Anwar, SaeedaKhanum and Sheikh \\ Ahmed. Pure and Applied Biology. Vol. 8, Issue 1, pp977-993. http://dx.doi.org/10.19045/bspab.2019.80039

\begin{tabular}{llll}
\hline \hline Received: 04/12/2018 & Revised: 05/03/2019 & Accepted: 07/03/2019 & Online First: 29/03/2019 \\
\hline \hline
\end{tabular}

\section{Abstract}

Lymphoma is a heterogeneous group of malignancies derived from the lymphoid system that accounts for roughly $4 \%$ of cancers worldwide. A significant improvement during the last decade was made possible with the introduction of an anti-CD20 monoclonal antibody, rituximab, which has been utilized widely in the treatment of B cell lymphomas leading to significantly better outcomes, which in part have contributed to the reduced mortality rates. Various factors like lifestyle, genetics, environment, age, ethnicity and gender are risk factors of lymphoma. Other factors include Socioeconomics, marital status, educational background, history of drinking or smoking and obesity. Globally, lymphoma is the sixth most common malignancy. HL is second most common lymphoma in developed countries whereas third most common malignancy in developing countries. NHL is eleventh most occurring cancer in males and eighth most common in female. Lymphoma is more common in men. In Pakistan HL accounts for $4.9 \%$ and NHL is approximately $4.7 \%$. Prevalence of lymphoma cancer in Balochistan is about $9.6 \%$.

Keywords: Angiogenic; Biological markers; Epidemiology; Hodgkin lymphoma; Lymphoma; Non-Hodgkin lymphoma

\section{Introduction}

\section{Lymphoma}

Lymphomas take place when cells of lymphatic system divide and re-divide in an uncontrolled fashion and lymphomas have been termed as a "diverse group" of cancer, playing a major role in the area of oncology [1]. Among hematological malignancies lymphoma is most common. The word 'lymphoma' covers various group of biologically and clinically distinctive neoplasms. Lymphoid cells are origin of lymphoma, on the bases of lymphoid cells are divided into B-cell lymphoma, T-cell lymphoma and natural-killer (NK)-cell lymphoma and HL. According to World Health Organization (WHO), about 90 subtypes as well as some basic types of lymphoma are classified. Progression of immunology and molecular biology discovered significant knowledge about the molecular mechanism on the basis of lymphogenesis and diagnosis of lymphoma [2]. Lymphoma originates by the cells of 
lymph system, and divided into two major types Hodgkin and non-Hodgkin lymphoma. These two types of lymphomas arise by immune cells like B-cells, T-cells, NK-cells [3].

In clinical medicine, comparison between malignant and benign lymphadenopathies is big diagnostic issue. Lymph nodes which are smaller than their normal sizes about few millimeters in metastatic deposits, then this create diagnostic task. In the subcutaneous areas, U/S (Ultra sound) looks most valuable technique for lymph node properties due to its high resolution $[4,5]$.

\section{Lymphatic system}

Cardiovascular and lymphatic systems are two mammalian circulatory systems [6]. Our body also contains these two types of circulatory systems e.g. blood and lymphatic systems. Widely studied circulatory system is cardiovascular system; less interest has been given to lymphatic system by science and medical due to its complicated morphology and mysterious pathophysiology. Innovative discoveries about lymphatic system changed the misunderstanding of people about this system, and is considered as second most important circulatory system [7].

Lymph angiogenesis is a process through which lymphatic system grows parallel with blood vascular system. Generally, some avascular organs like epidermis, cartilage, nails, hair, cornea and few vascularized organs as brain and retina do not contain lymphatic vessels. Normal growth and pathological development studies clarified the control of angiogenic process by the molecular mechanisms, absence of exact lymphatic markers and growth factors are reasons of slowed down studies about lymphatic system. Thus, about the growth and development of lymphatic system and its parts in diseases, our knowledge is in progressive phase [8]. Lymphatics, lymph nodes and lymphoid organs collectively make network of vessels for lymphatic system. There are two types of lymphoid organs named primary and secondary organs. Thymus and bone marrow are primary organs responsible for growth and development of lymphocytes, and secondary organs like spleen, payer's patches, appendix, the tonsils and the nodes work for additional growth and origination of an immune response [9].

key for absorption of dietary fats is lymphatic system [10]. During normal physiology network of vessels through lymphatic system plays vital role e.g. tissue fluid homeostasis maintained by lymphatic capillaries which absorb extravagated fluid and transfer that again to venous circulation through superior lymphatic vessels. Further, lymph vessels play a vital role by providing a path for antigen presenting cells (White Blood Cells) from peripheral surrounding to lymph nodes where immune responses start. Inappropriately, from tumors their malignant cells discharge and move along the lymphatic regions to lymph nodes and through circulation cause metastasis in some other organs [11]. In history, lymphatic vessels were known as impassive members in tumor metastasis by draining lymph nodes and providing tumor cells transportation [12]. Till-today, tumor cell transportation through lymphatic system and their journey between lymphatic and blood vessels are not clear [13].

\section{Epidemiological features of lymphoma}

Lymphoma malignancy is the commonest malignancy throughout the world. Distribution of its subtypes vary globally [14]. Solid tumors of immune system is known as lymphoma, about $90 \%$ of all lymphomas account for NHL and $10 \%$ for HL [15]. Our knowledge about lymphoma subtype distribution is limited yet, because for many years lymphoma was treated as single disease than heterogeneous group of distinct neoplasm [16].

Global burden of diseases considered lymphoid neoplasm (LN) as sixth most 
common malignancy. In 2012, NHL caused 0.2 million deaths considered as 11th most common cause of cancer mortality worldwide [17]. Among pediatric malignancies 10 to $15 \%$ account for lymphomas. HL is more treated with 5-year survival rates above $95 \%$ and for NHL this is $82 \%$ [18]. In developed countries Hodgkin lymphoma (HL) is the third most common malignancy, whereas in developing countries after acute leukemia, HL is in the second most common [19]. Among world $0.5 \%$ of cancer with an Age Standardized Rate (ASR) of $0.9 / 100,000$ accounts for Hodgkin lymphoma. Comparison between Asians and European, Asians have low HL frequency [20].

Generally NHL is eighth most diagnosed cancer cases for males and eleventh for women [21, 22]. By all NHL cases 30\% accounts for diffuse large B-cell lymphoma as the most common subtype [23]. NonHodgkin's lymphoma subtype Prevalence is different throughout the world [24].

In Punjab, prevalence of both lymphoma types like Hodgkin and non-Hodgkin are more common in men. Mixed cellularity (MC) and diffuse small cell are most common histopathological subtypes vary than western world. Tuberculous lymphadenitis is commonest lymphadenopathy in females with prevalence of $53 \%$, most involved lymph node is cervical [25]. In Karachi (Sindh), Non-Hodgkin lymphoma as the most sixth common malignancy of both men and women with prevalence reported respectively about 9.6/100,000 and $7.2 / 100,000$. In Northern Pakistan, NHL is the most common malignancy in men. This might be because of Inheritance, environmental and infectious elements combination [26]. In Khyber Pakhtunkhwa (KPK) province, metastatic lymph nodes led to tuberculosis which is the most common reason for cervical lymphadenopathy. Proper treatment depends on better diagnosis, so before biopsy FNAC (fine needle aspiration cytology) must follow [27].In Balochistan, $9.6 \%$ cases of malignant lymphoma registered in cancer hospital CENAR (Center for nuclear Medicine and Radiotherapy) [28]. For many years frequencies of lymphoma is rising, globally [29]. Depending on age, sex, ethnicity and histology NHL is different among children and adults [30]. Third most common cancer for children is non-Hodgkin lymphoma [31]. In all children malignancies is about $7 \%$ for NHL. After mature B-cell lymphoma, second most common NHL is lymphoblastic lymphoma which is considered as one third of all NHL in children [32]. In Pakistan Cancerous tumors are more common in children than children of developed countries. Diffuse large B-cell lymphoma (DLBCL) is most common subtype of NHL, Burkett's lymphoma considered as second more common subtype and primary tumours of bone are accounts for $3^{\text {rd }}$ most common NHL in children [33].

High lymphoma frequency in any country is directed to high incidences of extra nodal involvement. Pakistan and Saudi Arabia are existing in the lymphoma belt, extra nodal lymphoma in these countries are above $50 \%$ [34]. NHL arises in the tissues other than lymph nodes like spleen, thymus and waldeyer ring are called primary extra nodal, which is about one third of all NHL. In many countries NHL arising from extra nodal site is among 25\%. Liver, lung, thyroid, skin, genitourinary tract, adrenals and bone are most common primary extra nodal sites with flank pain as commonest presenting symptom [35]. Worldwide frequency of extra nodal lymphoma is increasing [36]. Gastrointestinal track, central nervous system and skin as extra nodal sites have increasing incidences by some years, the reasons can be environmental factors, immunosuppressive treatment and disorder like AIDS, chronic and autoimmune infections [37]. 
As a rare condition, primary bone marrow lymphoma (PBL) accounts about 7 to $5 \%$ respectively for primary bone cancers and extra nodal lymphomas. Even though bone involvement might be originating in progressive stage of lymphoma arising by other sites, lymphoma initially arises in the bone other than any place of body known as PBL. Among our country patients of all groups, DLBCL is the most common type of primary bone lymphoma. Hip bone followed the femur as the most involved sites, in men these are more common [38].

In lymphoma malignancy, ovary is familiar for involvement of late manifestation of nodal disease. Primary ovarian lymphoma is one of the rare malignancy. Approximately $0.5 \%$ of all NHL accounts for primary ovarian non-Hodgkin lymphoma and 1.5\% for complete ovarian lymphomas. More common primary ovarian NHL is DLBCL [39].

More commonly lymphoid malignancies are arising in elderly people e.g. among all neoplasms one half mean 54\% malignancies diagnosed in persons aged 65 and above. Distribution of age varies between various subtypes. Unlike other malignancies, lymphoma cancer is most common childhood malignancy. In children About two- thirds of malignancies are lymphomas [40].

There is a wide variation in the prevalence of various subtypes of non-Hodgkin's lymphoma worldwide [24]. In all Asian countries incidences of lymphoma subtypes are different [2]. The incidences of T-cell and natural-killer cell lymphomas are different with different geographies. In Asia, T-cell lymphomas are more predominant than Europe and North America and natural-killer cells are more prevalent in Asia and South America. Low incidences mean due to diagnosis and optimum treatment have not studied prospectively based on Randomized Controlled Trials (RCT) [41]. In Southern Pakistan especially in the province of Sindh, incidence of T-cell lymphomas is high as compared to Northern Pakistan. This shows an important geographic variation of this country directed to NHL immune-phenotypic position [42].

Frequencies of NHL histological subtypes differ among various geographic regions. In Asian countries, frequencies of follicular lymphoma (FL) and small lymphocytic lymphoma (SLL) are lower. Although T-cell lymphomas are considerably higher. These differences may arise by inherited susceptibility and several factors of environment [43].

These days the epidemiological research is going to explore the hematological cancer. The main focus is to distinguish the different types of hematological cancers on the basis of features and cause of the disease [44]. The treatment of cancer is more expensive than the treatment of all the other non communicable and lethal diseases of the world. In 2016, most common cancer cases of Pakistan are breast, leukaemia, Hodgkin and non-Hodgkin lymphoma. Hodgkin lymphoma is $4.9 \%$ and non-Hodgkin lymphoma $4.7 \%$. In Pakistan the lack of an appropriate registry system leads to widespread of cancer [45]. Lymphomas and breast cancer are the most common cancers. Lymphomas are common in males while breast cancer in female, comparatively, in the Asian specific region Lahore is found to be with the highest rates [46].

Epidemiologists have great attention towards lymphoma for several reasons; first Hodgkin and NHL both have an etiology of infectious and immune-suppression. Secondly, incidence of HL show different age distribution, so HL and NHL considered as two various diseases with different significant environmental factors [47]. In Pakistan, increasing population with limited incomes like many systems ignored cancer registry for many years. Registration of any disease comprising cancer is challenging 
work for developing countries and also for our country Pakistan [48]. Pakistan is included in the list of South- West Asian countries and with population of 173 million. Each year cancer prevalence is rising by 150 000 new cases with mortality rate about 60 to $70 \%$. In our country no proper information is available in national base about frequency of this disease [49].

Province Balochistan is spread on about $(347,190$ sq. $\mathrm{km})$ area in the map of Pakistan and said to be the largest province with population of 6.5 million. Naturally rich province with inorganic resources on the other hand limited communal and physical set-up like health sector, it is included in the list of backward provinces. Behind the backwardness is deficiency of hospitals, qualified doctors, absence of modern equipments and trained staff (compounders and nurses), people behavior towards traditional treatment and deficiency of therapeutic agents [50]. Cancer diagnosis and treatments is done at only one hospital CENAR (Center for nuclear Medicine and Radiotherapy) in Quetta. At CENR hospital, not only the patients of Balochistan but from outside of Pakistan including Iran and Afghanistan come for their treatment [51].

Socio-economic status (SES) is significant parameter for treatment outcomes of cancer. Poor education and late diagnosis are directly related with Socio-economic status. It is required to know involvement of educational and Socio-economic support among the helpless people [52].

\section{Investigation or diagnosis and staging}

In many countries of the world, most centers play a part for routine diagnosis of lymphomas by using big selection of lymphoid antibodies for immune-histochemistry (IHC) [53]. Rather on any specific marker there are various markers on the basis of numerous morphological diagnosis, containing B-cell markers like CD20 and 79a, markers of T-cell (CD3 and CD5), leukocyte common marker (LCA), and related to cyto-architectural pattern following markers are available CD10,CD23,CD15,CD30,CD128,cyclin D1,ALK1,bcl-2 [22].

Hodgkin lymphoma are classified as nodular lymphocyte predominance Hodgkin disease HD (NLP HL) and classic Hodgkin disease (CHD) histologically characterized by neoplastic cells and reactive cellular background. Based on WHO classification nodular sclerosis (NS), lymphocyte rich, mixed cellularity (MC) and lymphocyte depletion are consisting as subtypes of Hodgkin disease. The term lymphocyte and histiocytic ( $\mathrm{L}$ and $\mathrm{H}$ ) cells used for neoplastic cells of NLP HD and CHD, therefore called Hodgkin's and Reed Stern Burg cells (HRS). EBV on the bases of morphology, phenotype and infectious structure make the difference between these neoplastic cells. Not only the nature of neoplastic cells but presence of nearby T-cells makes different phenotypes for NLP HD and HD. CD57L and CD40L are positive phenotypes for NLP HD and HD respectively [54].

For diagnosis and staging of lymphoma disease one investigation method is bone marrow biopsy (BMB). In our country because of late staging of many patients bone marrow infiltration is very common method [55]. Bone marrow involvement does not likely exist in Initial stages (I and II) of HL therefore bone marrow biopsy must be stopped in early stages though it may be carried out in clinically progressive stages [56]. Comparison between patients without and with bone marrow infiltration leukocytosis and anemia indicated high incidence rates [57]. Bone marrow biopsy is significant as a regular staging method for both hematologic and non- hematological cancer patients. Second biopsy morphological examination can raise the involvement of bone marrow by 11 to $12 \%$ [58]. 
Proper therapy selection needs exact diagnosis and staging calculations. More commonly diagnostic system used for NHL as well as HL is Ann Arbor staging system, however this system cannot fit for diagnosis of some NHL subtypes. In 1993, international prognostic index developed for those subtypes and their causes for helping treatment outcomes. Application of these systems are important for new patients diagnosed by NHL. Protein and gene expression methods are current methods for staging of lymphoma proved from sixth addition of Cancer Staging Manual by American joint commission on cancer [59].

As soon as malignant lymphomas get diagnosed, the second step is to make treatment procedures based on degree of disease. Groups of three markers like serological, immune-phenotypic and molecular markers (known as biological markers of NHL) are used. Amongst the serological markers B2m reveals the burden of tumor and lymphoma aggressive abilities can be directed with LD [60].

DNA microarrays expression can lead the expression of genes in malignancies of Bcell. Clinically important and undiagnosed cancer subtypes detected through gene expression related with tumors molecular classification [61].

Germinal center and non-germinal center (non-GCB) lymphomas are subtypes of DLBCL [62]. Diffused large B-cell lymphoma molecular subtypes differentiate based on many systems related to immunohistochemistry. The Hans algorithm extensively use system, which show that in Asia frequency of non-GCB is common than western world [63]. For diagnosis of DLBCL lymphoid antibodies like CD20, CD79a, Pax5 and Ki-67 are used and for subtyping of DLBCL CD10, BCL-6 and MUM-1 used as monoclonal antibody [64].

In Pakistani people, DLBCL of Germinal center type frequency by CD10 and BCL6 expressions are about $37.5 \%$ and for non GCB type DLBCL expression by MUM-1 accounts $62.5 \%$. This subtype frequency is greater than western countries required appropriate planning based on its findings. Proper diagnosis and complete providing of required markers can help patients for better treatment [65].

$\mathrm{PET} / \mathrm{CT}$ is admirable technique for lymphoma staging and involvement of bone marrow application related with lymphoma. High involvement of bone marrow in HL and DLBCL identified by PET/CT than BMB. Without any negative results this method is useful for selecting exact biopsy place with concord of BMB [66].

F-FDG-PET is good but not a brilliant technique for staging a lymphoma cases with results of $\mathrm{BMB}$ by infiltration bone marrow through detection. The BMB results compliment with F-FDG PET and its activity vary depends on lymphoma types [67]. For staging of HL in patients, F-FDG-PET/CT with BMB plays a part of complementary. Though in this field, prospective studies required for more explanation and conformational role of FDG-PET/CT [68].

\section{Risk factors or causes of lymphoma}

Immune dysfunction as well as infected persons by HIV are causes for rising HL and NHL in people, still there is few information that how much HL and NHL are effected by immunological and virological factors [69]. In Pakistan, among most common lymphoproliferative conditions, the cause of this disease is still unknown. While in endemic areas of the world, Epstein Bar Virus(EBV) is familiar risk factor for HL, but its relation with our population is not broadly studied. Immunohistochemistry (IHC), In situ hybridization (ISH), and polymerase chain reaction $(\mathrm{PCR})$ are different methods for identification of EBV. Latent membrane protein 1 (LMP1), LMP2a, EBV nuclear antigen 1 (EBNA1), EBV small nuclear RNA transcripts (EBER), and the Bam HI A region 
transcripts are subsets of EBV genes for EBV infected tumors of HL by epidemiological studies $[46,70]$. Infected tumor, among all these markers EBVR and LMP1 are most commonly used.

Corresponding ratio of NHL subtypes between developing countries and among developing and rest of the world probably arise from variation of environmental and genomic factors that affect lymphagenesis and strongly advise more research in developing world may offer appreciated awareness about the lymphoid neoplasms (LN) pathogenesis [53].

Increasing body mass index is related with high risk of cancer either common or noncommon cancer [71]. Relation of obesity with malignant lymphomas are vary among Asian and European people[72]. Obesity and overweight can be a risk factors for nonHodgkin lymphoma [73].

In Pakistan rising tendency of cancer rate may be connected with deficiency of food, changing in nutritional habits, poor Socioeconomic status, reducing physical activity and growing tendency of tobacco, eating pan and bitternut [70]. Relation of environmental and genetic factors show significant role, thus it is required to know appropriately about these risk factors and do work for reduction of this complete issue. It is important to know about cancer risk factors and to start communication among various parties for fighting of this disease [74].

Lymphoma types or subtypes distribution by differences in Age, gender and ethnicity.

\section{Age}

lymphoma neoplasm is generally known in aged ones as compared with other cancer forms [40]. As a rare lymphoma, Hodgkin disease effects both younger and adult individuals [75].About all cases of lymphoma one in four are accounted as Hodgkin lymphoma rare. Hodgkin lymphoma subtypes vary among younger and adult cases, NS (nodular Sclerosis) seems to be more common in younger individuals whereas mixed cellularity (MC) is in older ones. Poor diagnosis of elderly cases than younger people examined by numerous studies [76]. People of any age can get effected by this disease but generally HL targets the persons aged between 15 and 49 [77]. Mixed cellularity is most common subtype of Hodgkin lymphoma in Pakistan than nodular sclerosis [78].

In older people non-Hodgkin (NHL) as a common tumor diagnosis is at the age of 67 . Globally, non-Hodgkin lymphoma frequencies have been raising for many years $[22,79]$. In elderly population NHL is gradually increasing as significant source of mortality and morbidity. More than 60 years of age are considered as adverse diagnostic source for non-Hodgkin lymphoma. Complete survival is directed with growing age, above 70 years aged patients show poor response than 60 to 70 years old patients. These results could be due to reasons like comorbidity and changing of pharmacokinetics by worse host tissue tolerance in older patients, bone marrow hematopoietic and microenvironment alteration with old ages related to treatment, difficulties like infections and cardiovascular issues due to increase rate of treatment. It is estimated that just because of old aged patients around 23\% receive possibly insufficient doses of chemotherapy [80].

Among all adult lymphomas about one third of non-Hodgkin lymphoma DLBCL subtype is most common. While sixth decade is diagnostic era for DLBCL by average age [81]. Not only DLBCL is most common Bcell non-Hodgkin lymphoma among older people but for children too [82]. Adult lymphoma varies from children based on non-Hodgkin lymphoma frequency, biology, treatment and outcome. Approximately 1 to $2 \%$ of adult lymphomas accounting for Burkett's lymphoma (BL) as aggressive Bcell NHL [83]. 
Sex

Gender variations related incidences and prognosis of many lymphoid malignancies cleared that men are more affected than women are (Figure 1). Molecular mechanism about this sexual differentiation is unknown yet. Protective role of estrogens beside nonHodgkin lymphomas clearly confirmed by few epidemiological statics [84]. Healthier resilience of women than men enlightened the phenomenon of higher lymphoma incidences in males [85].
Male to female ratio of small B-cell NHL is 2:1 and nodal to extra nodal appearance is about ratio of 3:4. comparison with Western literature it is lower in Pakistan [86]. In developing world, the male to female ratio of lymphoma cases accounts approximately (5:1) for Pakistan. Gender discrimination is on dominant phase that could be one cause. Male to female ratio of 5:1 for patients from developing countries like Pakistan is not clearly understood. One reason may be gender discrimination still prevalent in many developing countries [19].

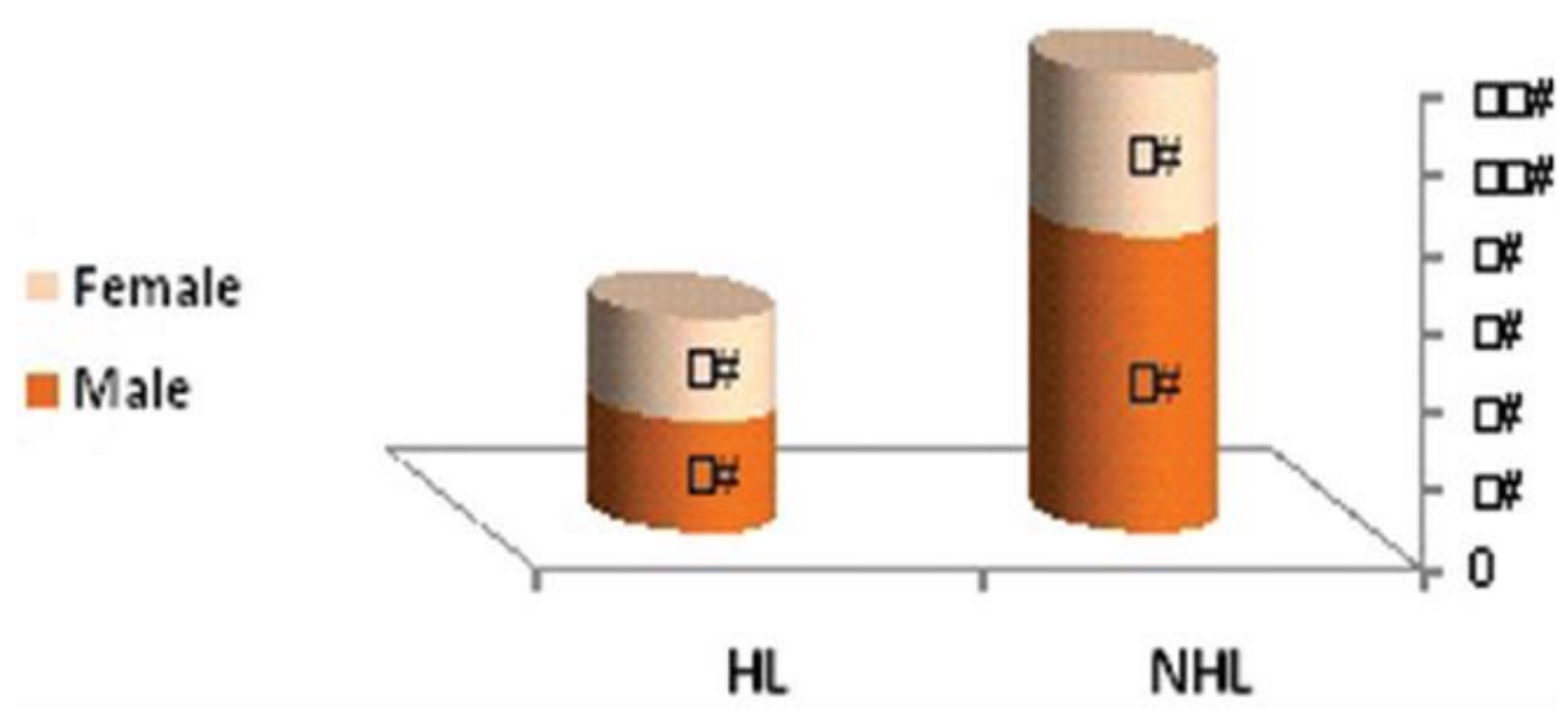

Figure 1. the sex of malignant lymphomas; HL and NHL[29]

\section{Ethnicity}

In health research origin of diseases and especially related environmental and genetic factors can be easily known by ethnicity [87]. Many cancers have been clarified by racial differences. Several studies based on major variations in frequency rates, characteristics of disease towards patient's survival by ethnicity. Though ethnic group of survival analysis on population based described by solid tumors of breast, lung ,colon and prostate with current information of multiple myeloma and nonHodgkin lymphoma [88].
Quetta is the largest city as well as capital of Balochistan. Population of Quetta consists of various ethnic groups including Baloch, Pathan (Pashtoon), Hazara, Punjabi and other ethnics. Only one hospital treats cancer cases named CENAR (Center for Nuclear Medicine and Radiotherapy) [89]. Quetta cancer data based on genetic, environmental and racial variations differ from Northwest province [90].

\section{Treatment}

Cancer chemotherapy history is as old as this disease. High Complications of cancer directed with presence of current anti-cancer 
agents fighting against progression of this disease. Improvement in chemotherapy needs a great attention. By ancient methods, many chemotherapeutic agents have been discovered; chemotherapeutic agents like, anti-tumor antibodies, anti-metabolites, alkylating agents, platinum compounds and natural products are in use. Broadly used treatment for cancer is hormones and compounds interfering with hormone metabolism as well as small molecules targeting angiogenesis and monoclonal antibodies [91]. Twentieth century is the era to use chemotherapy for cancer cure. With significant molecular abnormalities used for screening and potential of fresh drugs along with targeting treatments, chemotherapy has been changed these days [92].

In oncology, Hodgkin lymphoma is most treatable malignancy. By chemotherapy and radiotherapy, more than $80 \%$ patients may be treated with risk-adapted treatment. Progression of techniques like multi-agent chemotherapy and better radiation are reasons for this improvement, but these life-saving treatments have side effects like second malignancy and toxicity of organs. Therefore, treatment procedures should be wisely balanced among optimum control of disease and the long- term squeal risks [93]. Chemotherapy and radiation together is $90 \%$ effective treatment for non-bulky HL casas but connected with late treatment cause deaths. Alone chemotherapy increase survival as less later deaths connected with it [94].

In 1964 an accumulated knowledge by procarbazine, different methods changed the program of the MOPP (mechlorethamine, vincristine, procarbazines and prednisone). Even though studies of MOPP changed the treatment of progressive disease of Hodgkin's, after MOPP treatment about 15 to $30 \%$ cases did not show better outcomes and approximately 20 to $30 \%$ responders moved back their early situations. These results show that this selective drugs failed to show better treatment results or recurrence of initial disease. Therefore, at the start of 1970s, limitations of MOPP or MOPP derived mixtures and fresh compounds encouraged many researchers for planning of new agents of chemotherapy and provide them for MOPP patients and replaced mixture of four MOPP drugs by them [95].

ABVD (Doxorubicin, bleomycin, vincristine and dacarbazine) discovered in the middle of 1970s for progressive HL treatment, with some toxic effects known as standard treatment because of more effective activity than MOPP [96].It is clear that ABVD is less toxic than MOPP treatment [97].

In favorable conditions of HL, two or four cycles of chemotherapy followed by 20 to 30 GY, while in advance stages six or eight cycles of chemotherapy is done. The better outcomes of radiotherapy than the alone chemotherapy cases who showed good results are not clear yet [98]. After 2 cycles of ABVD treatment, more disease control showed by patients as compare with cases which did not get this result, 5- years survival outcomes of advance disease are same as patients who get CMT (combined modality therapy) [99]. The combination of chemotherapy containing ABVD with radiotherapy showed better effectiveness by allowing low chemo dose and radiation field, leads to extensive use of collective technique methods in early cases of $\mathrm{HL}$ and encouraging diagnosis. Involved field of $30 \mathrm{GY}$ radiation therapies with four ABVD cycles are considered as standard of care by many groups. Chemotherapy alone is considered as another different technique but still controversial [100].

However, there are various epidemiological profiles from developing countries with excellent outcomes by chemotherapy alone is good in children HL cases [101]. At this time CMT is standard treatment for CHL early patients and radiotherapy is for aggressive cases. Alone chemotherapy method is sensible for some cases related with appropriate 
properties [102]. In early stages of HL with favorable conditions CMT results are better than alone chemotherapy. Though every patient might deal with separate basis as favorable disease in young female, only chemotherapy can be superior decision because there is risk of breast cancer related with radiotherapy. Safe regimen in between 2nd and 3rd trimester for women are ABVD [103].

Combination of ABVD chemotherapy with IFRT (Involve-Field Radio Therapy) is an active and less toxic in HL early stages together with unfavorable and favorable conditions. Two cycles of ABVD followed by radiation has five year satisfactory outcomes about $93 \%$ related with alone ABVD modality is $87 \%$ [104].

International Working Formulation (IFW) classified that about $50 \%$ of NHL patients have aggressive histology of types $\mathrm{E}$ to $\mathrm{H} 1$ and Revised European-American Lymphoma Classification has classified few types. Among them common subtype is DLBCL, CHOP (Cyclophosphamide, doxorubicin, vincristine and prednisone) is standard treatment for patients other than Burritt's and Lymphoblastic Lymphoma (LBL). Aggressive non-Hodgkin lymphoma cases with CHOP have approximately 80 to $90 \%$ overall responses rates (ORRS), complete response rates (CR) of 40 to $55 \%$ and 5-year survival rate of about 30 to $40 \%$ [105].

CHOP is standard treatment for in aggressive elderly cases. Yet no any multi regimen is proved to be superior than CHOP. Patients with high doses of CHOP related with autologous hematopoietic stem cells show superb results [106]. CHOP in every 3 weeks is standard for aggressive lymphomas. Even though COEP (Cyclophosphamide, doxorubicin, vincristine, etoposide) is considered best chemotherapy for young aggressive cases with normal LDH level [107].
Monoclonal antibody like Rituximab is a unique antibody used for NHL treatment. This antibody has high binding affinity to those cells that contains CD20 antigen on the surface of benign and cancerous B-cells. This antibody has properties of inducing apoptosis and sensitizing chemo resistant lymphoma cells in human [108]. In low grade NHL patients Rituximab is highly active and show $48 \%$ response rate [109]. By adding rituximab in CHOP and applying eight cycles with freshly diagnosed DLBCL old patients show complete response and this treatment low the treatment failure rates and increases overall survival by comparing CHOP alone [110]. Rituximab also increase survival rate of nongerminal center (non-GCB) DLBCL patients [111].

Rituximab with CVP (cyclophosphamide, vincristine, and prednisone) is standard treatment for follicular lymphoma, which has $60 \%$ to $80 \%$ response rates. Without any toxic effects it show better outcomes by clinically untreated progressive follicular cases [112]. Rituximab combined with ESHAP (Etoposide, methylprednisolone (solumedrol), high-dose cytarabine (ara-C) and cisplatin) show toxicity in aggressive NHL patients [113].

\section{Conclusion}

Lymphoma cancer is one of most common lymphoid malignancies throughout the world. In developing countries, it is second most common malignancy. In Pakistan the frequency of Hodgkin and non-Hodgkin lymphoma rising, several characteristics can take part for progression of this disease such as life style, Socio-economic status, age, gender inherited, environmental and infectious factors. In our country most of cases diagnosed in advance stages. In Pakistan, especially in Balochistan this problem is painful because of illiteracy, unawareness of people who belongs to backward or rural areas. Lymphoma is big issue for people of any age because of non-availability of cancer 
hospitals and highly paid clinical laboratories, people go outside for diagnosis of lymphoma or any other cancer. Late detection because of deficiency of advance equipments, doctors fail to timely diagnose malignant cases. There is no any pathology or histopathological department, majority of cases are referred to Agha Khan University Karachi for better and timely diagnosis and some patients go to Shaukat Khanam Memorial Cancer Hospital Lahore. Some poor patients cannot meet the expense of this process so many cases remain undiagnosed. Proper registry system is not available therefore; cancer registry is a big challenge for epidemiologists. Unsatisfactory records make future planning difficult. In Pakistan and in Balochistan the first step for health programs should be in local wise to focus the epidemiology, frequency and risk factors of this disease so management and controlling will take stepwise. People of Balochistan directly feels the absence of a cancer hospital and, there is just small cancer hospital which is not sufficiently equipped to treat patients affected by cancer. Private or outside histo-pathological centers are expensive for the local population. Therefore, the current research is meant to enable Government has to establish cancer hospital in Balochistan in order to provide people of Balochistan the facilities to get cancer treatment.

Better survival of this disease is linked with increasing awareness among the population. Therefore, it is emphasized that government of Balochistan has to launch a large scale awareness campaign in every district of the province. It becomes an important role of the educated class of the society to spread awareness among public for a meaningful social welfare organized movement.

\section{Authors' contributions}

Conceived and designed the study: S Shabbir, Analyzed the data: S Shabbir, Wrote the paper: S Shabbir.

\section{References}

1. Word ZH \& Matasar MJ (2012). Advances in the diagnosis and management of lymphoma. Blood and Lymphatic Cancer: Targets and Therapy (2): 29-55.

2. Suzumiya J (2018). Current status and progress of lymphoma research in East Asian countries: Introduction and planning. Inter J Hematol 107(4): 392394.

3. Hosseini SA, Tahmoorespur M, Sekhavati MH \& Nassiri M (2016). Construction and cloning of a recombinant expression vector containing human $\mathrm{Cd} 20$ Gene for antibody therapy in Non-Hodgkin Lymphoma. Hormoz Med J 20(3):177184.

4. Chiorean L, Barr RG, Braden B, Jenssen C, Cui XW, Hocke M \& Dietrich CF (2016). Transcutaneous ultrasound: Elastographic lymph node evaluation. Current clinical applications and literature review. Ultrasound Med Biol 42(1): 16-30.

5. Janovská P \& Bryja V (2017). Wnt signalling pathways in chronic lymphocytic leukaemia and B-cell lymphomas. Br J Pharmacol 174(24): 4701-4715.

6. Aspelund A, Robciuc MR, Karaman S, Makinen T \& Alitalo K (2016). Lymphatic system in cardiovascular medicine. Circulation Res 118(3): 515530.

7. Choi I, Lee S \& Hong YK (2012). The new era of the lymphatic system: no longer secondary to the blood vascular system. Cold Spring Harb Perspect Med 2(4): a006445.

8. Oliver G \& Detmar M (2002). The rediscovery of the lymphatic system: old and new insights into the development and biological function of the lymphatic vasculature. Genes Dev 16(7): 773-783. 
9. Margaris KN \& Black RA (2012). Modelling the lymphatic system: challenges and opportunities. $J R S o c$ Interface 9(69): 601-612.

10. Semo J, Nicenboim J \& Yaniv K (2016). Development of the lymphatic system: new questions and paradigms. Development 143(6): 924935.

11. Alitalo K \& Carmeliet P (2002). Molecular mechanisms of lymphangiogenesis in health and disease. Cancer cell 1(3): 219-227.

12. Christiansen A \& Detmar M (2011). Lymphangiogenesis and cancer. Genes \& cancer 2(12): 1146-1158.

13. Pang MF, Georgoudaki AM, Lambut L, Johansson J, Tabor V, Hagikura K \& Jakobsson L (2016). TGF- $\beta 1$-induced EMT promotes targeted migration of breast cancer cells through the lymphatic system by the activation of CCR7/CCL21-mediated

chemotaxis. Oncogene 35(6): 748.

14. Monabati A, Safaei A, Noori S, Mokhtari M \& Vahedi A (2016). Subtype distribution of lymphomas in South of Iran, analysis of 1085 cases based on World Health Organization classification. Ann Hematol 95(4): 613618.

15. Shankland KR, Armitage JO \& Hancock BW (2012). Non-hodgkin lymphoma. The Lancet 380(9844): 848857.

16. Ito D, Frantz AM \& Modiano JF (2014). Canine lymphoma as a comparative model for human non-Hodgkin lymphoma: recent progress and applications. Vet Immunol Immunopathol 159(3-4): 192-201.

17. Mondal SK, Mandal PK, Samanta TK, Chakaborty S, Roy SD \& Roy S (2013). Malignant lymphoma in Eastern India: A retrospective analysis of 455 cases according to World Health Organization classification. Indian $\mathrm{J}$ Med Paediatr Oncol 34(4): 242.

18. Frew JA, Lewis J \& Lucraft HH (2013). The management of children with lymphomas. Clin Oncol 25(1): 11-18.

19. Faizan M, Taj MM, Anwar S, Asghar N, Ahmad A, Lancaster D \& Ali AS (2016). Comparison of presentation and outcome in 100 pediatric Hodgkin lymphoma patients treated at Children Hospital, Lahore, Pakistan and Royal Marsden Hospital, UK. J Coll Physicians Surg Pak 26(11): 904-907.

20. Ziaullah S, Ahmad S, Khan MM, Alam S, Nasir S \& Sharif N (2017). Epstein barr virus lmp-1 positivity in hodgkin lymphoma subtypes, in khyber Pakhtunkhwa province of Pakistan. Gomal J Med Sci 15(1).

21. Boffetta P (2011). I. Epidemiology of adult non-Hodgkin lymphoma. Ann Oncol 22(4): 27-31.

22. Sharma M, Mannan R, Madhukar M, Navani S, Manjari M, Bhasin TS \& Gill KS (2014). Immunohistochemical (IHC) analysis of Non-Hodgkin's lymphoma (NHL) spectrum according to WHO/REAL classification: A single centre experience from Punjab, India. $J$ Clin Diagn Res 8(1): 46.

23. Castillo JJ, Winer ES \& Olszewski AJ (2014). Sites of extranodal involvement are prognostic in patients with diffuse large B-cell lymphoma in the rituximab era: an analysis of the surveillance, epidemiology and end results database. Am J Hematol 89(3): 310-314.

24. Ameen R, Sajnani KP, Albassami A \& Refaat S (2010). Frequencies of nonHodgkin's lymphoma subtypes in Kuwait: comparisons between different ethnic groups. Ann Hematol 89(2): 179.

25. Naseem S, Bilal S, Akhlaq M, Henna N, Sami W, Nagi A \& Ashraf M (2011). A pattern of lymphadenopathies seen in a tertiary care hospital in Lahore, 
Pakistan. Turk J Med Sci 41(2): 353358.

26. Lal A, Bhurgri Y, Vaziri I, Rizvi NB, Sadaf A, Sartajuddin S \& Masood N (2008). Extranodal non-Hodgkin's lymphomas--a retrospective review of clinico-pathologic features and outcomes in comparison with nodal nonHodgkin's lymphomas. Asian Pac J Cancer Prev 9(3): 453-458.

27. Shimaoka K, Sokal JE \& Pickren JW (1962). Metastatic neoplasms in the thyroid gland. Pathological and clinical findings. Cancer 15(3): 557-565.

28. ul Haq N, Pal AW, Nasim A, Razaque G, Riaz S \& Zeeshan M (2016). Prevalence of Cancer Types In Patients Attending Cenar Cancer Hospital Quetta, Pakistan. Value Health 19(3): A135.

29. Humam MA, Al-Nakhbi NA, Melkat AA, Almontaser TM \& Binnabhan AS (2016). Malignant lymphoma in Hadhramout Sector, Yemen: a retrospective study of 170 cases classified according to the WHO classification. J Curr Med Res Pract 1(2): 6.

30. Binesh F, Akhavan A, Behniafard N \& Atefi A (2014). Clinicopathologic and survival characteristics of childhood and adolescent non Hodgkin's lymphoma in Yazd, Iran. Asian Pac $J$ Cancer Prev 15(4): 1585-1588.

31. Stone DK \& Brown BJ (2014). NonHodgkin Lymphoma. In Pediatric Hematology-Oncology in Countries with Limited Resources. Springer 271290.

32. Lazic J, Janic D, Krstovski N, Rodic P, Milosevic G, Jankovic S \& Dokmanovic L (2016). Lymphoblastic lymphomas in children-A single-center experience from Serbia. Srp Arh Celok Lek 144(78): 413-417.
33. Jamal S, Mamoon N, Mushtaq S \& Luqman M (2006). Pattern of childhood malignancies: study of 922 cases at Armed Forces Institute of Pathology (AFIP), Rawalpindi, Pakistan. Asian Pac J Cancer Prev 7(3): 420.

34. Bangash MH, Hussain I, Zakaria M \& Piracha MN (2014). Pattern of extranodal involvement in non hodgkin s lymphoma. Pak Armed Forces Med $J$ 64(4): 605-8.

35. Pinggera GM, Peschel R, Buttazzoni A, Mitterberger M, Friedrich A \& Pallwein L (2009). A possible case of primary renal lymphoma: a case report. Cases J 2(1): 6233.

36. Padhi S, Paul TR, Challa S, Prayaga AK, Rajappa S, Raghunadharao D \& Sarangi R (2012). Primary extra nodal non Hodgkin lymphoma: a 5-year retrospective analysis. Asian Pac J Cancer Prev 13(10): 4889-95.

37. Sultan S, Irfan SM, Rashid A, Parveen S \& Nawaz N (2017). Clinicohematological Profile of 184 Patients with Non-Hodgkin's Lymphoma: An Experience from Southern Pakistan. Gulf J Oncolog 1(25): 11-14.

38. Qureshi A, Ali A, Riaz N \& Pervez S (2010). Primary non-hodgkin's lymphoma of bone: experience of a decade. Indian J Pathol Micr 53(2): 267.

39. Elharroudi T, Ismaili N, Errihani H \& Jalil A (2008). Primary lymphoma of the ovary. J Cancer Res Ther 4(4): 195.

40. Teras LR, Desantis CE, Cerhan JR, Morton LM, Jemal A \& Christopher R (2016). 2016 US lymphoid malignancy statistics by World Health Organization subtypes. CA Cancer J Clin 66(6): 443459.

41. Kwong YL, Anderson BO, Advan R, Kim WS, Levine AM \& Lim ST (2009). Management of T-cell and naturalkiller-cell neoplasms in Asia: consensus 
statement from the Asian Oncology Summit 2009. Lancet Oncol 10(11): 1093-1101.

42. Muzaffar S, Pervez S, Aijaz F, Aziz SA \& Hasan SH (1997). Immunophenotypic analysis of non-Hodgkin's lymphoma. $J$ Pak Med Assoc 47(4): 106.

43. Cozen W, Kavianpour B \& Mack TM (2018). The Epidemiology of Hodgkin Lymphoma. Springer 157-196.

44. Roman E \& Smith AG (2011). Epidemiology of lymphomas. Histopathol 58(1): 4-14.

45. Sarwar MR, Iftikhar $\mathrm{S} \&$ Saqib A (2018). Availability of anticancer medicines in public and private sectors, and their affordability by low, middle and high-income class patients in Pakistan. BMC Cancer 18(1): 14.

46. Masood A, Masood K, Hussain M, Ali W, Riaz M, Alauddin Z \& Shahid A (2018). Thirty years cancer incidence data for Lahore, Pakistan: trends and patterns 1984-2014. Asian Pac J Cancer Prev 19(3): 709.

47. Grufferman S (2018). Epidemiology and Hereditary Aspects of Hodgkin and Non-Hodgkin Lymphomas. Springer 755-772.

48. Badar F \& Mahmood S (2017). Epidemiology of cancers in Lahore, Pakistan, among children, adolescents and adults, 2010-2012: a cross-sectional study part 2. BMJ open 7(12): e016559.

49. Yusuf A (2013). Cancer care in Pakistan. Jpn J Clin Oncol 43(8): 771775.

50. Naseem S, Khattak UK, Ghazanfar H \& Irfan A (2017). Maternal health status in terms of utilisation of antenatal, natal and postnatal services in a Periurban setting of Islamabad: A community based survey. J Pak Med Assoc 67(8): 1186-1191.

51. Khan NF, Saeed M, Butt AK \& Khan AA (2017). Epidemiology of Head and
Neck Neoplasm's in Balochistan. J Pak Dent Assoc 26(03): 119.

52. Biasoli I, Castro N, Delamain M, Silveira T, Farley J, Pinto Simões B \& Franceschi F (2018). Lower socioeconomic status is independently associated with shorter survival in Hodgkin Lymphoma patients-An analysis from the Brazilian Hodgkin Lymphoma Registry. Inter $J$ Cancer 142(5): 883-890.

53. Naresh KN, Advani S, Adde M, Aziz Z, Banavali S, Bhatia K \& Norton A (2004). Report of an International Network of Cancer Treatment and Research workshop on non-Hodgkin's lymphoma in developing countries. Blood Cell Mol Dis 33(3): 330-337.

54. Carbone A, Gloghini A, Aldinucci D, Gattei V, Dalla-Favera R \& Gaidano G (2002). Expression pattern of MUM1/IRF4 in the spectrum of pathology of Hodgkin's disease. BrJ Haematol 117(2): 366-372.

55. Hamid A, Hamid A, Jabbar N \& Naeem S (2010). Significance of Bone Marrow Biopsy in Staging of Hodgkinâ Lymphoma. Ann King Edward Med Uni 16(1 SI).

56. Anwar R, Iqbal U J \& Ahmad N (2015). Frequency of Bone Marrow Involvement in Hodgkin's Lymphoma in Patients Presented at Shoukat Khanum Memorial Cancer Hospital Lahore. Pak J Med Health Sci 9(4): 1347-1349.

57. Sultan S, Irfan SM, Parveen S \& Ali S (2016). Clinico-Hematological Findings for Classical Hodgkin's Lymphoma: an Institutional Experience. Asian Pac J Cancer 17(8): 4009-4011.

58. Wang J, Weiss LM, Chang KL, Slovak ML, Gaal K, Forman SJ \& Arber DA (2002). Diagnostic utility of bilateral bone marrow examination: significance of morphologic and ancillary technique 
study in malignancy. Cancer 94(5): 1522-1531.

59. Armitage JO (2005). Staging nonHodgkin lymphoma. Cancer $J$ Clin 55(6): 368-376.

60. Mazher N, Ahmad N \& Iqbal Z (2017). Correlation of patterns of bone marrow infiltration and biochemical factors in non-Hodgkin lymphoma. Pak J Med Sci 33(2): 462.

61. Alizadeh AA, Eisen MB, Davis RE, Ma C, Lossos IS, Rosenwald A \& Powell JI (2000). Distinct types of diffuse large Bcell lymphoma identified by gene expression profiling. Nature 403(6769): 503.

62. Athar S, Siddiqui N, Rai SR., Muzaffar $N$ \& Hameed A (2015). Impact of rituximab and IPI on survival in diffuse large B cell lymphoma patients treated at a tertiary level cancer centre in pakistan: A single-centre experience. Bone 4(18): 19-4.

63. Snak Y, Indrawati KW, Arfian N \& Anggorowati N (2018). Molecular subtypes, apoptosis and proliferation status in indonesian diffuse large B-cell lymphoma cases. Asian Pac J Cancer Prev 19(1): 185.

64. Bukhari U, Lateef F \& Jamal S (2015). Frequency of Subgroups of Diffuse Large B-Cell Lymphoma by Immunohistochemistry. $J$ Liaquat Uni Med Health Sci 14(2): 78-82.

65. Bajwa A, Khadim M, Din H, Ali SS, Jamil U \& Khan UAS (2017). Immunohistochemical expression of CD10, BCL6 and MUM1 in differentiating diffuse large B Cell lymphoma subtypes. J Coll Physicians Surg Pak 27: 621-4.

66. Cortés-Romera M, Sabaté-Llobera A, Mercadal-Vilchez S, Climent-Esteller F, Serrano-Maestro A, Gámez-Cenzano C \& González-Barca E (2014). Bone marrow evaluation in initial staging of lymphoma: 18F-FDG PET/CT versus bone marrow biopsy. Clin Nucl Med 39(1): 46-52.

67. Pakos EE, Fotopoulos AD \& Ioannidis JP (2005). 18F-FDG PET for evaluation of bone marrow infiltration in staging of lymphoma: a meta-analysis. $J$ Nucl Med 46(6): 958-963.

68. Muzahir S, Mian M, Munir I, K Nawaz M, S Faruqui Z, A Mufti K \& $\mathrm{T}$ Mahmood M (2012). Clinical utility of $18 \mathrm{~F}$ FDG-PET/CT in the detection of bone marrow disease in Hodgkin's lymphoma. Br J Radiol 85(1016): 490496.

69. Shepherd L, Ryom L, Law M, Hatleberg CI, de Wit S, Monforte ADA \& Pradier $C$ (2017). Differences in virological and immunological risk factors for nonHodgkin and Hodgkin lymphoma. $J$ Natl Cancer Inst 110(6): 598-607.

70. Hashmi AA, Hussain ZF, Hashmi KA, Zafar MI, Edhi MM, Faridi N \& Khan M (2017). Latent membrane protein 1 (LMP1) expression in Hodgkin lymphoma and its correlation with clinical and histologic parameters. World J Surg Oncol 15(1): 89.

71. Renehan AG, Tyson M, Egger M, Heller RF \& Zwahlen M (2008). Body-mass index and incidence of cancer: a systematic review and meta-analysis of prospective observational studies. The Lancet 371(9612): 569-578.

72. Kanda J, Matsuo K, Suzuki T, Hosono S, Ito H, Ichinohe T \& Tanaka H (2010). Association between obesity and the risk of malignant lymphoma in Japanese: a case-control study. Inter $J$ Cancer 126(10): 2416-2425.

73. Larsson SC \& Wolk A (2007). Obesity and risk of non-Hodgkin's lymphoma: A meta-analysis. Int J Cancer 121(7): 1564-1570. 
74. Waly MI \& Rahman MS (Eds.) (2018). Bioactive Components, Diet and Medical Treatment in Cancer Prevention. $1^{\text {st }}$ Ed. Springer; (Newyork).

75. Nagi AH, Al-Menawy LA, Naveed IA \& Sami W (2008). A comparison of histological appearances of Hodgkin's disease in Pakistani and Saudi patients. $J$ Ayub Med Coll Abbottabad 20(3): 6669.

76. Stark GL, Wood KM, Jack F, Angus B, Proctor SJ, Taylor PR \& Northern Region Lymphoma Group (2002). Hodgkin's disease in the elderly: a population-based study. $\mathrm{Br} \quad J$ Haematol 119(2): 432-440.

77. Avagyan A, Danielyan S, Voskanyan A, Sargsyan L, Hakobyan L, Zohrabyan D \& Arakelyan S (2016). Treating Adults with Hodgkin Lymphoma in the Developing World: A Hospital-Based Cohort Study from Armenia. Asian Pac J Cancer Prev 17: 101-104.

78. Jamal A, Khatoon S, Junejo A \& Rasool B (2008). Frequency of Hodgkin's Lymphoma in Patient with Cervical Lymphadenopathy Presenting in a Public Hospital in Pakistan. J Liaquat Uni Med Health Sci 7(3): 173-176.

79. Wang M, Burau KD, Fang S, Wang H \& Du XL (2008). Ethnic variations in diagnosis, treatment, socioeconomic status, and survival in a large population-based cohort of elderly patients with non-Hodgkin lymphoma. Cancer: Interdisciplinary Inter $J$ of the American Cancer Soc 113(11): 3231-3241.

80. Bairey O, Benjamini O, Blickstein D, Elis A \& Ruchlemer R (2006). NonHodgkin's lymphoma in patients 80 years of age or older. Ann Oncol 17(6): 928-934.

81. Shenoy PJ, Malik N, Nooka A, Sinha R, Ward KC, Brawley OW \& Joseph L (2011). Racial differences in the presentation and outcomes of diffuse large B-cell lymphoma in the United States. Cancer 117(11): 2530-2540.

82. Klapper W, Kreuz M, Kohler CW, Burkhardt B, Szczepanowski M, Salaverria I \& Schwanen C (2012). Patient age at diagnosis is associated with the molecular characteristics of diffuse large B-cell lymphoma. Blood 119(8): 1882-1887.

83. Oosten LEM, Chamuleau MED, Thielen FW, de Wreede LC, Siemes C, Doorduijn JK, \& Demandt AMP (2018). Treatment of sporadic Burkitt lymphoma in adults, a retrospective comparison of four treatment regimens. Ann Hematol 97(2): 255-266.

84. Hasni MS (2015). Estrogens and lymphoma growth. Inst for biovetenskaper och naringslara/Dept of Biosciences and Nutrition.

85. Dwianingsih EK, Hardianti MS, Malueka RG, Iswar RR, Sutapa SA \& Triningsih FX (2016). Histopathological Features of Lymphoma in Yogyakarta, Indonesia. Asian Pac J Cancer Prev 17(9): 4213-4216.

86. Aftab K, Bhurgri Y \& Pervez S (2006). Small B cell non-Hodgkins lymphoma in Pakistan. J Pak Med Assoc 56(1): 22.

87. Pahwa P, Karunanayake CP, Spinelli JJ, Dosman JA \& McDuffie HH (2009). Ethnicity and incidence of Hodgkin lymphoma in Canadian population. BMC cancer 9(1): 141.

88. Evens AM, Antillon M, AschebrookKilfoy B \& Chiu BH (2012). Racial disparities in Hodgkin's lymphoma: a comprehensive population-based analysis. Ann Oncol 23(8): 2128-2137.

89. Yousafzai A, Ahmed N, Luqman M, Naseeb Hk, Hashmi N, Rani K \& Wali A (2017). Clinical presentation and lifestyle related risk Factors of breast cancer among different age and ethnic 
groups. Indo Am. j. pharm. Sci 4 (11): 4464-4475.

90. Bhurgri Y, Bhurgri H, Ajam A, Pervez S, Hasan SH, Usman A \& Bhurgri A (2002). Cancer patterns in Quetta (19981999). J Pak Med Assoc 52(12): 560.

91. Masood I, Kiani MH, Ahmad M, Masood MI \& Sadaquat H (2016). Major contributions towards finding a cure for cancer through chemotherapy: a historical review. Tumori

Journal 102(1): 6-17.

92. DeVita VT \& Chu E (2008). A history of cancer chemotherapy. Cancer Res 68(21): 8643-8653.

93. Borchmann P, Eichenauer DA \& Engert A (2012). State of the art in the treatment of Hodgkin lymphoma. Nat Rev Clin Oncol 9(8): 450.

94. Meyer RM, Gospodarowicz MK, Connors JM, Pearcey RG, Wells WA, Winter JN \& Crump M (2012). ABVD alone versus radiation-based therapy in limited-stage Hodgkin's lymphoma. $N$ Engl J Med 366(5): 399-408.

95. Bonadonna G, Zucali R, Monfardini S, de Lena M \& Uslenghi C (1975). Combination chemotherapy of Hodgkin's disease with adriamycin, bleomycin, vinblastine, and imidazole carboxamide versus MOPP. Cancer 36(1): 252-259.

96. Viviani S, Zinzani PL, Rambaldi A, Brusamolino E, Levis A, Bonfante V \& Valagussa P (2011). ABVD versus BEACOPP for Hodgkin's lymphoma when high-dose salvage is planned. $N$ Engl J Med 365(3): 203-212.

97. Delwail V, Jais JP, Colonna P \& Andrieu JM (2002). Fifteen-year secondary leukaemia risk observed in 761 patients with Hodgkin's disease prospectively treated by MOPP or ABVD chemotherapy plus high-dose irradiation. Br J Haematol 118(1): 189194.
98. Diehl V, Thomas RK \& Re D (2004). Part II: Hodgkin's lymphomadiagnosis and treatment. Lancet Oncol 5(1): 19-26.

99. Meyer RM, Gospodarowicz MK, Connors JM, Pearcey RG, Bezjak A, Wells WA \& Djurfeldt MS (2005). Randomized comparison of ABVD chemotherapy with a strategy that includes radiation therapy in patients with limited-stage Hodgkin's lymphoma: National Cancer Institute of Canada Clinical Trials Group and the Eastern Cooperative Oncology Group. $J$ Clin Oncol 23(21): 4634-4642.

100. Engert A, Plütschow A, Eich HT, Lohri A, Dörken B, Borchmann P \& Debus J (2010). Reduced treatment intensity in patients with early-stage Hodgkin's lymphoma. N Engl Med J 363(7): 640652.

101. Trehan A, Singla S, Marwaha RK, Bansal D \& Srinivasan R (2013). Hodgkin lymphoma in children: experience in a tertiary care centre in India. J Pediatr Hematol Oncol 35(3): 174-179.

102. Iberri DJ, Hoppe RT \& Advani RH (2015). Hodgkin lymphoma: the changing role of radiation therapy in early-stage disease - the role of functional imaging. Curr Treat Options Oncol 16(9): 45.

103. Ali S, Basit A, Kazmi AS, Sidhu A, Badar F \& Hameed A (2016). Chemotherapy alone or combined chemotherapy and involved field radiotherapy in favorable risk earlystage classical Hodgkin lymphoma-a 10 years experience. Pak J Med Sci 32(6): 1408.

104. Bonadonna G, Bonfante V, Viviani S, Di Russo A, Villani F \& Valagussa P (2004). ABVD plus subtotal nodal versus involved-field radiotherapy in early-stage Hodgkin's disease: long- 
term results. J Clin Oncol 22(14): 28352841.

105. Vose JM, Link BK, Grossbard ML, Czuczman M, Grillo-Lopez A, Gilman P \& Fisher RI (2001). Phase II study of rituximab in combination with $\mathrm{CHOP}$ chemotherapy in patients with previously untreated, aggressive nonHodgkin's lymphoma. $J$ Clin Oncol 19(2): 389-397.

106. Milpied N, Deconinck E, Gaillard F, Delwail V, Foussard C, Berthou C \& Harousseau JL (2004). Initial treatment of aggressive lymphoma with high-dose chemotherapy and autologous stem-cell support. N Engl J Med 350(13): 12871295.

107. Pfreundschuh M, Trümper L, Kloess M, Schmits R, Feller AC, Rübe C \& Hasenclever D (2004). Two-weekly or 3-weekly CHOP chemotherapy with or without etoposide for the treatment of elderly patients with aggressive lymphomas: results of the NHL-B2 trial of the DSHNHL. Blood 104(3): 634641.

108. Grillo-López AJ (2000, December). Rituximab: an insider's historical perspective. In Seminars in Oncol 27(6): 9-16.

109. Hainsworth JD, Burris HA, Morrissey LH, Litchy S, Scullin D C, Bearden JD \& Greco F A (2000). Rituximab monoclonal antibody as initial systemic therapy for patients with low-grade non-
Hodgkin lymphoma. Blood 95(10): 3052-3056.

110. Pfreundschuh M, Trümper L, Österborg A, Pettengell R, Trneny M, Imrie K \& Stahel R (2006). CHOP-like chemotherapy plus rituximab versus CHOP-like chemotherapy alone in young patients with good-prognosis diffuse Large-B-cell lymphoma: a randomised controlled trial by the MabThera International Trial (MInT) Group. Lancet Oncol 7(5): 379-391.

111. Li ZM, Huang JJ, Xia Y, Zhu YJ, Zhao W, Wei WX \& Guan Z (2012). High Ki67 expression in diffuse large B-cell lymphoma patients with non-germinal center subtype indicates limited survival benefit from R-CHOP therapy. Eur $j$ Haematol 88(6): 510-517.

112. Marcus $\mathrm{R}$, Imrie $\mathrm{K}$, Belch $\mathrm{A}$, Cunningham D, Flores E, Catalano J \& Jack A (2005). CVP chemotherapy plus rituximab compared with CVP as firstline treatment for advanced follicular lymphoma. Blood 105(4): 1417-1423.

113. Harting R, Venugopal P, Gregory SA, O'brien T \& Bogdanova E (2007). Efficacy and safety of rituximab combined with ESHAP chemotherapy for the treatment of relapsed/refractory aggressive B-cell non-Hodgkin lymphoma. Clin Lymphoma and Myeloma 7(6): 406-412. 